\title{
$\mathrm{Al}-\mathrm{Si}$ 도금층 두께가 22MnB5강의 핫스탬핑 공정 마모에 미치는 영향

\author{
지민기 ${ }^{1}$ · 손현성 ${ }^{2}$ · 오진근 ${ }^{3}$ · 김성우 ${ }^{3}$ - 김경목 ${ }^{4}$ - 전태성 ${ }^{1,5, *}$ \\ 1인천대학교 기계공학과 \\ ${ }^{2} \mathrm{POSCO}$ 기술연구원 성형연구그룹 \\ ${ }^{3} \mathrm{POSCO}$ 기술연구원 자동차소재연구그룹 \\ 4한국항공대학교 항공우주 및 기계공학부 \\ 5 인천대학교 공학기술연구소
}

\section{Effects of Al-Si Coating Thickness on 22MnB5 in Hot Stamping Wear}

\author{
Min Ki Ji ${ }^{1}$, Hyunsung $\mathrm{Son}^{2}$, Jinkeun $\mathrm{Oh}^{3}$, Seongwoo $\mathrm{Kim}^{3}$, Kyungmok Kim${ }^{4}$, and Tea-Sung Jun ${ }^{1,5, *}$ \\ ${ }^{1}$ Department of Mechanical Engineering, Incheon National University, Incheon 22012, Republic of Korea \\ ${ }^{2}$ Materials Forming Research Group, Steel Solution Research Lab., POSCO, Incheon 21985, Republic of Korea \\ ${ }^{3}$ Automative Steel Research Group, Technical Research Laboratories, POSCO, Gwangyang 57807, Republic of Korea \\ ${ }^{4}$ School of Aerospace and Mechnical Engineering, Korea Aerospace University, Gyeonggi 10540, Republic of Korea \\ ${ }^{5}$ Research Institute for Engineering and Technology, Incheon National University, Incheon 22012, Republic of Korea
}

\begin{abstract}
Al-Si coated ultra-high strength steels (UHSS) are widely used in automotive applications because of their high strength-to-weight ratio, corrosion protection and good weldability. The hot stamping (also called hot press forming) process is an effective and suitable technique for producing automotive parts from Al-Si coated UHSS. However, critical issues, such as the transfer of the coating materials and the build-up of these materials on the tool surface, have been encountered. These defects affect tool life and product quality. The wear behaviour of Al-Si coated 22MnB5 and Cr coated SKD11 tool was investigated using a high temperature friction test which mimicked the actual hot stamping environment. Two kinds of Al-Si coated 22MnB5 with $\sim 19.6$ (AlSi-A) and $~ 29.3$ (AlSi-B) pm coating thicknesses were used in this study. After the friction test the coated layer of AlSi-A was found to be worn up to the diffusion layer, while for AlSi-B, the coating layer mostly remained after the friction test. Adhesive wear predominantly occurred on the tool surface in both cases, but the wear increased significantly in case of AlSi-B. This suggests that the coating thickness and the associated surface roughness are critical factors affecting wear behaviour.
\end{abstract}

(Received June 9, 2020; Accepted June 25, 2020)

Keywords: friction, wear, hot stamping, Al-Si coating, ultra-high strength steel

\section{1. 서 론}

최근 고유가 시대 및 환경 규제가 강화됨에 따라 자동차 연비 향상을 목적으로 한 차체 경량화의 필요성이 급증하 고 있으며 가볍고 안전성을 높인 소재가 개발되어 상용화 단계에 있다. 경제성 및 환경친화성 등의 강점을 갖는 철 강 소재 역시 활발한 연구개발이 이루어져 고성능의 철강

- 지민기: 석사과정, 손현성·오진근·김성우: 연구원, 김경목·전태성: 교수 ${ }^{*}$ Corresponding Author: Tea-Sung Jun

[Tel: +82-32-835-8034, E-mail: t.jun@inu.ac.kr]

Copyright $(C)$ The Korean Institute of Metals and Materials
재료들이 잇따라 개발되고 있으며 그 중 인장강도 $1 \mathrm{GPa}$ 이상의 초고강도강(Ultra-High Strength Steel, UHSS)이 차세대 자동차 구조용 강재로 주목받고 있다 [1,2]. 강도의 증가에 따른 성형성 감소의 일반적인 소재 특성으로 인해 초고강도강이 개발된 초기 단계에는 차체 구조용 등에 적 용하는데 어려움이 있었으나, 이는 핫스탬핑 (또는 핫프레 스포밍) 공정이 개발됨에 따라 점차 개선되었다 [3-6]. 핫 스탬핑은 그림 1 에서 보는 것처럼 강판을 가열로에 통과 시켜 열처리를 한 후 금형 프레스에서 성형과 냉각을 동시 에 시행하는 공정이다.

핫스탬핑 공정에 주로 사용되는 $22 \mathrm{MnB} 5$ 강판은 초기에 


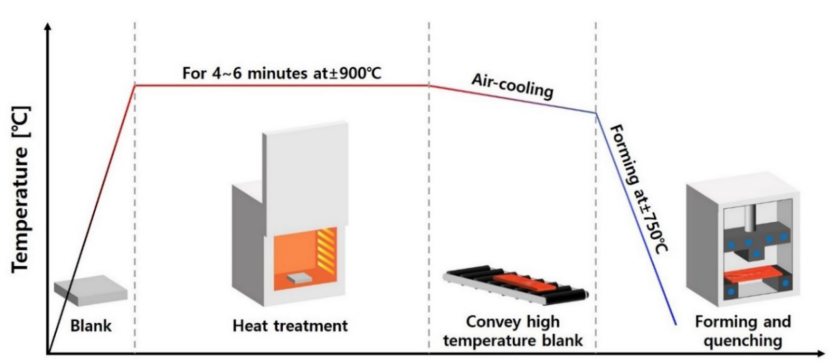

Fig. 1. Schematic of hot stamping processing and temperature.

페라이트와 펄라이트로 구성된 미세조직을 시작으로 $900^{\circ} \mathrm{C}$ 부근에서 4 6분간 열처리를 통해 오스테나이트 단상으로 변태된다 $[7,8]$. 이 후 금형에서 성형과 급랭을 동시에 시 행하여 오스테나이트를 마르텐사이트로 변태시켜 최종적으 로 $1.5 \mathrm{GPa}$ 이상의 초고강도강을 제작할 수 있다 [8-11]. 고온 공정 중 산화 스케일 등의 위험에 노출된 강판을 위 해 여러 도금재가 연구 되었으며[12], 이 중 $\mathrm{Al}-\mathrm{Si}$ 도금재 가 산화와 부식 측면에서 뛰어났다. 결과적으로 $\mathrm{Al}-\mathrm{Si}$ 도 금재는 핫스탬핑 공정에서 널리 적용되었다.

$\mathrm{Al}-\mathrm{Si}$ 도금강을 대상으로 한 핫스탬핑 공정은 강도 측면 에서의 뛰어난 이점과 동시에 마모에 대한 취약점 또한 공 존한다. 고온의 강판은 급랭 시 수축하게 되며 동시에 금 형과 강판 간에 마찰이 발생하게 된다 [13]. 이로 인해 성 형 후 금형과 강판 표면에 $\mathrm{Al}$ 과 $\mathrm{Fe}$ 계열의 금속간화합물 이 존재하는 이른바 '소착'현상[14]이 발생하게 되며 이는 생산품의 품질 저하 및 금형의 수명 단축 측면에서 결함으 로 작용한다. 이와 같은 마모에 대한 취약점을 해결하고자 다양한 연구가 진행되어 왔다. Hardell과 Pelcastre는 모재 와 도금의 종류[13], 금형의 표면 조도[15,16], 열처리 조 건[17] 등의 측면에서 핫스탬핑 공정 마모를 Pin-on-disc 형식의 왕복 마찰 방식을 통해 분석하였지만, 매번 새로운 강판을 성형하는 핫스탬핑 공정에 모사하기에는 방법론적 인 한계점이 존재하였다. 이에 Venema[18]는 핫스탬핑 공 정을 모사하고자 기존의 왕복 마찰 방식이 아닌 고온 평면 마찰('Strip drawing test') 방식을 이용하여 마찰 시험 온 도에 따라 마모 거동을 분석하였지만 소착 현상에 대한 구 체적인 원인 규명은 제시하지 못한 실정이다.

따라서 본 연구에서는 평면 마찰 방식의 자체 제작한 마 찰기와 가열로의 적용을 통해 핫스탬핑 공정을 모사하여 $\mathrm{Al}-\mathrm{Si}$ 도금층 두께에 따른 $22 \mathrm{MnB} 5$ 강의 핫스탬핑 마모에 대한 영향을 도금층, 고온 마찰 및 금형 마모 측면에서 비 교 분석해 보았다.
Table 1. Chemical composition of the 22MnB5(wt\%)

\begin{tabular}{ccccc}
\hline $\mathrm{C}$ & $\mathrm{Mn}$ & $\mathrm{Si}$ & $\mathrm{Cr}$ & $\mathrm{B}$ \\
\hline $0.2 \sim 0.3$ & $1.1 \sim 1.25$ & $0.2 \sim 0.3$ & $0.13 \sim 0.25$ & $0.002 \sim 0.004$ \\
\hline
\end{tabular}
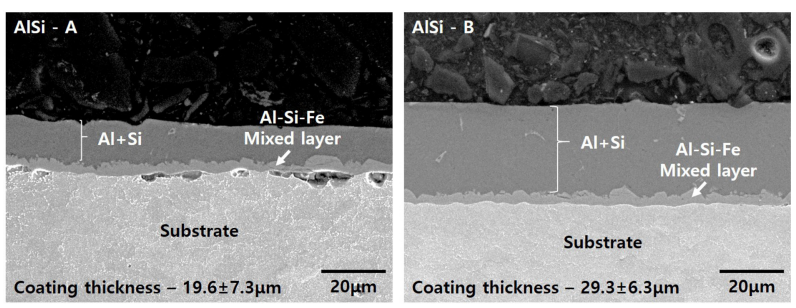

Fig. 2. Initial phase distribution on the as-received Al-Si coating.

\section{2. 시험 방법}

시험에 사용된 소재는 시중에 판매 중인 $\mathrm{Al}-\mathrm{Si}$ 도금된 $22 \mathrm{MnB} 5$ 강이며 모재의 OES(Optical Emission Spectrometry) 분석을 통한 화학조성은 표 1 과 같다.

핫스탬핑 공정에서 $\mathrm{Al}-\mathrm{Si}$ 도금층 두께에 대한 영향을 비 교 분석하기 위하여 모재 및 도금층 종류가 동일하며 도금 층 두께만 다른 두가지 소재를 선정하였다. 본 연구에서 두께가 비교적 얇은 소재를 $\mathrm{AlSi}-\mathrm{A}$, 두꺼운 소재를 $\mathrm{AlSi}-$ $\mathrm{B}$ 로 정의하였으며 소재의 초기 도금층은 그림 2 와 같다. 초기에는 합금화가 진행되지 않은 $\mathrm{Al}$ 과 $\mathrm{Si}$ 이 지배적으로 존재하였으며 도금층과 모재 사이에는 $\mathrm{Al}, \mathrm{Si}, \mathrm{Fe}$ 가 혼합 된 층이 확인되었다. 해당 층은 $\mathrm{AlSi}-\mathrm{A}$ 소재에서 $\mathrm{Al}$ $55.46, \mathrm{Si} 9.55, \mathrm{Fe} 33.65 \mathrm{wt} \%$ 로, $\mathrm{AlSi}-\mathrm{B}$ 의 경우 $\mathrm{Al}$ $55.11, \mathrm{Si} 9.09$ 그리고 $\mathrm{Fe}$ 가 $33.9 \mathrm{wt} \%$ 로 검출되었다. 도 금층 두께는 $\mathrm{AlSi}-\mathrm{A}$ 에서 약 $19.6 \pm 7.3 \mu \mathrm{m}$, AlSi-B는 약 $29.3 \pm 6.3 \mu \mathrm{m}$ 로 $\mathrm{AlSi}-\mathrm{B}$ 소재에서 좀 더 두꺼운 도금층을 확인할 수 있었다. 열처리는 $900{ }^{\circ} \mathrm{C}$ 에서 6 분간 시행하였으 며 열처리 시편 크기는 마찰 시편과의 크기 영향(size effect)을 고려하여 $130 \times 75 \times 1.4 \mathrm{~mm}^{3}$ 판재로 열처리 후 중앙 부분에 $10 \times 10 \mathrm{~mm}^{2}$ 정사각형 시편의 단면으로 도금 층을 분석하였다.

핫스탬핑 공정을 모사하기 위하여 가열로와 마찰기로 고 온의 마찰 환경을 구성하였다. 가열로는 Lenton사의 AWF$12 / 25$ 모델을 이용하였으며 마찰기는 자체 제작하였다. 기 존에는 마찰 및 마모 특성을 분석하기 위하여 pad-ondisc[19], pin-on-disc[20], ball-on-plate[21], pin-on-plate [22] 등 왕복 운동형 마찰시험기를 이용하였다. 왕복 마찰 시험기는 일반적으로 위쪽 금형과 아랫쪽 판으로 구성되어 있으며 시험 동안 일정 트랙을 따라 반복된다. 이를 핫스 
(a)
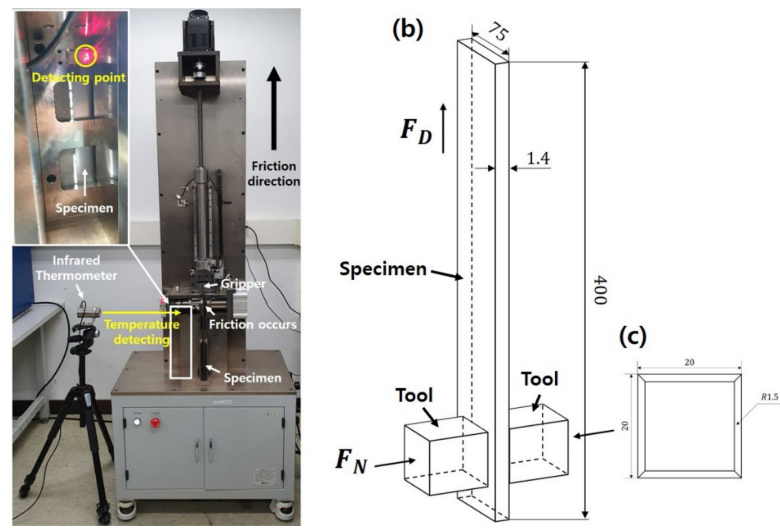

Fig. 3. Illustration and schematic of friction test components: (a) friction test machine, (b) testing method and (c) tool surface (all dimensions in $\mathrm{mm}$ ).

탬핑 공정을 모사하는데 접목할 시 위쪽 금형을 성형기의 금형, 아랫쪽 판을 강판으로 가정할 수 있다. 금형 측면에 서 시험 초기에는 마모가 되지 않은 강판과의 마찰이지만 시험이 거듭 될수록 부분적으로 마모가 발생한 강판과의 반응이며 이는 새로운 강판을 성형하는 핫스탬핑 공정을 모사하기에는 한계점이 존재한다고 판단된다. 이러한 한계 점을 보완하기 위하여 본 연구에서는 'Strip drawing test' 방식 [9]을 기반으로 제작한 마찰시험기를 사용하였다. 그림 3은 마찰기 형상과 마찰 시험 방법 및 금형의 모식도이다. 해당 마찰기를 이용하여 도출한 마찰 계수 $(\mu)$ 는 다음과 같 은 식으로 나타낸다.

$$
\mu=\frac{F_{D}}{2 F_{N}}
$$

위 식에서 $\mathrm{F}_{\mathrm{D}}$ 는 마찰 시편을 당기는 힘을 나타내며 $\mathrm{F}_{\mathrm{N}}$ 은 마찰 중 금형이 시편에 부가하는 힘이다. 마찰 시편은 $400 \times 75 \times 1.4 \mathrm{~mm}^{3}$ 크기로 제작되었고, 금형은 $\mathrm{SKD} 11$ 공 구강에 $\mathrm{Cr}$ 으로 표면처리를 하였으며 경도값은 $58.2 \pm 0.4$ $\mathrm{HRC}$ 였다. 금형 크기는 $20 \times 20 \times 9 \mathrm{~mm}^{3}$ 에 육면체 형상이 었으며 마찰하는 면의 끝 부분은 $1.5 \mathrm{~mm}$ 로 라운드 처리를 하였다. 제작한 마찰기의 반복성과 신뢰성을 확인하기 위 하여 이미 검증된 평면 마찰기와 동일한 금형, 시편, 마찰 조건으로 상온 비교 마찰 시험을 시행하였다. 시험을 3 회 반복 시행하였으며 일반적으로 2 개의 유효 숫자를 가지는 마찰 계수[23]를 보다 신뢰성 높게 분석하기 위해 소수점 3 째자리 까지 값을 비교하여 이를 표 2에 정리하였다. 표 준편차값과 마찰 계수 평균값을 통해 본 마찰기의 반복성 과 신뢰성을 확인하였다.

마찰 시험 중 시간에 따른 온도를 측정하기 위하여
Table 2. Comparison of friction coefficient between conventional and newly developed friction test machine.

\begin{tabular}{ccc}
\hline No. of friction tests & $\mu_{\text {Conventional }}$ & $\mu_{\text {Newly developed }}$ \\
\hline 1 & 0.131 & 0.133 \\
2 & 0.129 & 0.123 \\
3 & 0.125 & 0.122 \\
\hline Average & 0.128 & 0.126 \\
Standard Deviation & 0.003 & 0.006 \\
\hline
\end{tabular}

Table 3. The parameters of a friction test that mimics the hot stamping environment.

\begin{tabular}{cc}
\hline Test parameters & Value \\
\hline Pressure & $5 \mathrm{MPa}$ \\
Heat treatment condition & $900{ }^{\circ} \mathrm{C} 6 \mathrm{~min}$ \\
Velocity & $100 \mathrm{~mm} / \mathrm{s}$ \\
Distance & $280 \mathrm{~mm}$ \\
\hline
\end{tabular}

OPTRIS사 적외선 온도계(CTlaser $3 \mathrm{MH} 2$ 모델)를 사용하 였다. 측정된 온도를 통해 시편이 $900{ }^{\circ} \mathrm{C}$ 에서 6 분 동안 열 처리가 된 후 상온에서 초당 약 $13{ }^{\circ} \mathrm{C}$ 씩 공냉이 됨을 확 인하였으며, 이를 근거로 핫스탬핑 공정의 조건과 유사하 게 $750{ }^{\circ} \mathrm{C}$ 부근에서 마찰이 일어날 수 있도록 모든 마찰 시험을 열처리 후 12 초 뒤에 시행할 수 있게 설계하였다. 고온 마찰 시험에 적용한 조건은 표3과 같다.

열처리에 따른 도금층 변화를 관찰하기 위해 시편의 단 면을 기계적 연마 후, Colloidal silica를 증류수(Distilled water)와 5:1 비율로 희석한 용액으로 미세 연마를 실시하 였다. 광학현미경(Optical microscope)으로 준비된 시편의 도금층과 확산층(Diffusion layer)등을 확인하였으며, 이를 통해 합금화가 이루어졌음을 판단하였다. 시편과 금형의 미 세조직 및 성분 분석을 위하여 JEOL사 JSM-7800F 모델 의 주사전자현미경(SEM, Scanning Electron Microscope) 과 Oxford instruments사의 에너지분산형 분광분석법(EDS, Energy Dispersive X-ray Spectroscopy)을 이용하였다. 이 후 도금층에 존재하는 금속간화합물들의 기계적 특성 분석 을 위하여 Anton Paar사의 나노압입시험기를 이용하였다. 압입 시험의 조건은 깊이 방향을 제어하여 $300 \mathrm{~nm}$ 까지 조 건을 설정하였으며 이전 압입 시험에 대한 영향을 최소화 하기 위하여 적어도 $30 \mu \mathrm{m}$ 이상 거리를 두고 시험을 시행 하였다. 또한 주사전자현미경으로 도금층 성분 분석하기 전 모재에 나노압입시험기로 별도의 마킹을 하여 성분 분석한 곳과 최대한 동일한 부분의 특성값을 확인하였다. 도금층 의 상온 경도는 Oliver-Pharr[24,25]의 방법을 이용하여 계 산하였다. 표면 조도는 Bruker사의 표면측정기를 이용하여 
열처리 전·후 시편을 분석하였다. $130 \times 75 \times 1.4 \mathrm{~mm}^{3}$ 크기 의 판재를 마찰 방향을 따라 반으로 자른 후, 한 개의 시 편만 동일한 조건에서 열처리 후 표면 조도를 분석하였다. 표면 조도 분석 시 하중은 $0.003 \mathrm{kgf}$, 분석 범위는 $3 \mathrm{~mm}$ 로 조건을 설정하였으며 동일한 면의 다른 부분으로 반복 수행하였다. 이때 육안 및 표면측정기의 현미경으로 분석 범위에 존재하는 스크래치 등 표면 결함의 유무를 우선적 으로 확인 후 분석을 시행하였다.

\section{3. 결과 및 고찰}

\section{1 열처리 후 합금화층}

그림 4 는 $900{ }^{\circ} \mathrm{C}$ 에서 6 분간 열처리 후 도금층 두께에 따른 합금화층을 나타낸다. 열처리 후 도금층은 기존의 $\mathrm{Al}$ 과 $\mathrm{Si}$ 의 상태에서 $\mathrm{Fe}-\mathrm{Al}$ 2원계 혹은 $\mathrm{Fe}-\mathrm{Al}-\mathrm{Si}$ 3원계[26] 금속간화합물을 이루고 있었으며 도금층 전체적으로 합금 화 되지 않은 $\mathrm{Al}$ 과 $\mathrm{Si}$ 원소는 관찰되지 않았다. 도금층 두 께가 비교적 얇은 $\mathrm{AlSi}-\mathrm{A}$ 의 경우, 도금층 상층부에는 산화 층과 $\mathrm{Fe}_{2} \mathrm{Al}_{5}$ 상이 존재하였다. 도금층 중앙 부분에는 비교 적 밝은 색의 층이 존재하는데, $\mathrm{EDS}$ 성분 분석 결과 $\mathrm{Al}$ 성분이 $\mathrm{Fe}_{2} \mathrm{Al}_{5}$ 상이 지배적으로 존재하는 합금화층과 비교 하였을 때 적었으며 이를 Jang[27]과 Kondratiuk[28]는 Low Aluminum Zone(LAZ)이라 보고하였다. 본 연구에서 시행한 열처리 조건과 유사한 조건으로 도금층을 분석한
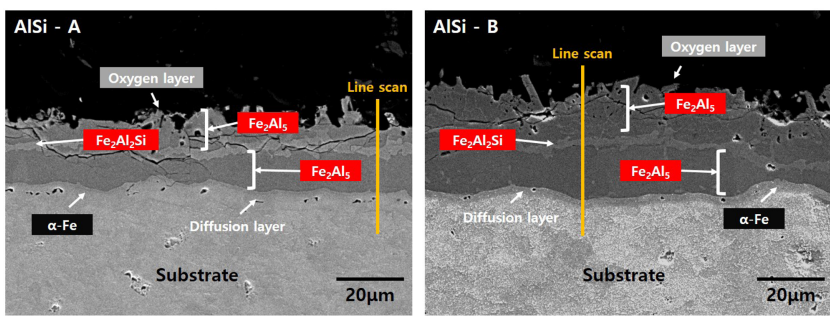

Fig. 4. Intermetallic compounds on the Al-Si coating after $6 \mathrm{~min}$ heat treatment at $900{ }^{\circ} \mathrm{C}$.
Veit[29]와 Pelcastre[17]는 LAZ의 상을 $\mathrm{Fe}_{2} \mathrm{Al}_{2} \mathrm{Si}$ 상으로 정 리하였으며, 이는 본 연구의 성분 분석 결과와 동일한 상 이다. $\mathrm{LAZ}$ 와 확산층 사이는 $\mathrm{Fe}_{2} \mathrm{Al}_{5}$ 상만 존재하였으며 확 산층(Diffusion layer)에서는 $\alpha-\mathrm{Fe}$ 상[30]이 지배적으로 검출 되었다.

각 상들의 기계적 특성 평가를 위하여 나노압입시험기를 이용하였다. 나노압입시험기 시험은 모재에 마킹한 곳을 기 준으로 성분 분석한 곳과 최대한 근접하게 시행하였으며 이를 도금층 전체적으로 반복 수행하였다. 푸아송 비는 $0.3[31]$ 으로 선정하였으며 압입부 형상을 근거로 모든 압입 시험은 도금층에 존재하는 크랙의 영향을 받지않도록 시행 하였다. 상온 경도값은 $\alpha-\mathrm{Fe}$ 상이 $508 \pm 53 \mathrm{Hv}, \mathrm{Fe}_{2} \mathrm{Al}_{5}$ 상이 $1162 \pm 12 \mathrm{Hv}, \mathrm{Fe}_{2} \mathrm{Al}_{2} \mathrm{Si}$ 상이 $875 \pm 20 \mathrm{Hv}$ 로 측정되었다. Matysik[31]는 나노압입시험기를 활용하여 Fe-Al계 금속간 화합물에 대한 특성을 정리하였으며 해당 결과와 본 연구 결과의 상 경도값은 유사하였다. 도금층 두께가 두꺼운 $\mathrm{AlSi}-\mathrm{B}$ 의 경우에도 $\mathrm{AlSi}-\mathrm{A}$ 소재와 유사한 도금층 구조를 확인할 수 있었으며 결과적으로 두 소재의 기존 도금층 두 께 차이에 따른 금속간화합물 측면에서는 영향이 미미한 것으로 사료되나 동일한 상이더라도 도금층에서 차지하는 두께 측면에서는 차이가 있는 것으로 판단된다.

그림 5 는 열처리 후 소재의 표면에 대한 성분 분석을 한 결과이다. 소재 표면에 대한 성분 분석한 결과, $\mathrm{Fe}$ 는 전체적으로 분포하였으며 $\mathrm{Al}$ 과 $\mathrm{O}$ 는 표면의 형태와 유사하 게 존재하였다. $\mathrm{Si}$ 의 경우 $\mathrm{Al}$ 과 $\mathrm{O}$ 의 분포와 유사하였지만 좀 더 전체적으로 분포하였다. $\mathrm{Al}$ 과 $\mathrm{O}$ 의 분포가 유사하게 존재하는 것을 통해 알루미늄계 산화물이 표면에 분포하는 것으로 판단하였으며, 해당 물질이 도금층에서 분포하는 정 도를 분석하기 위하여 그림 4의 노란색 선으로 나타낸 것 처럼 도금층의 단면부에서 주사전자현미경을 이용하여 Line scan을 시행하였고 이를 동일한 시편 도금층의 다른 부분 을 통해 각 3 회 반복하였다. 이에 대한 결과는 그림 6에 나타내었다.
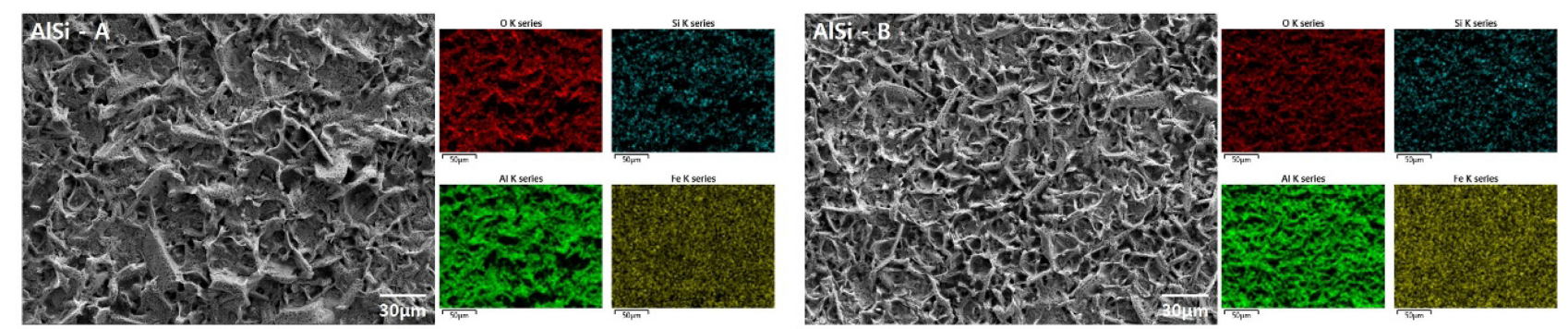

Fig. 5. Surface components analysis using SEM after heat treatment for 6 min at $900{ }^{\circ} \mathrm{C}$; AlSi-A(left) and AlSi-B(right). 
(a)

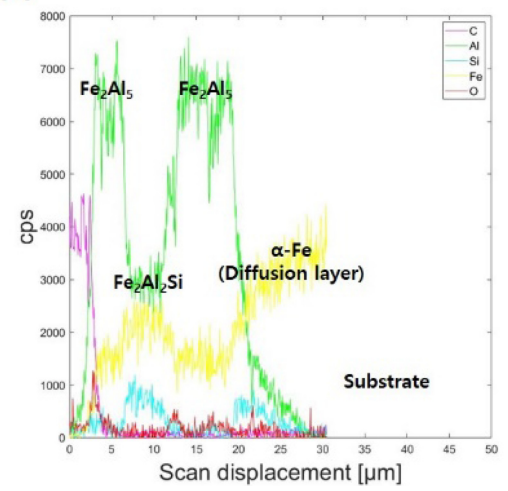

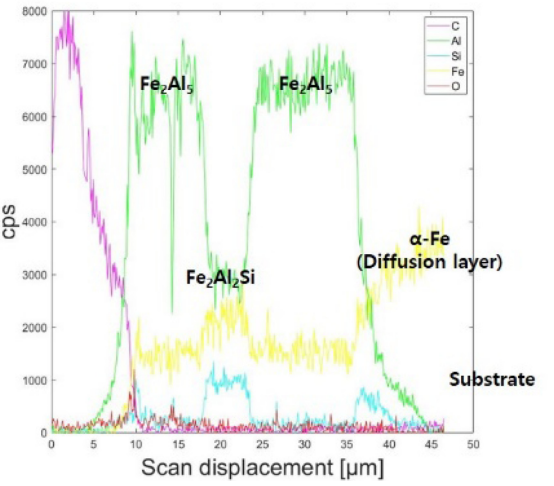

(b)

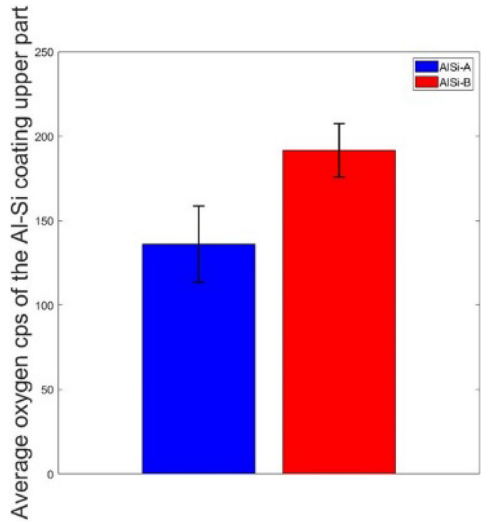

Fig. 6. Distribution of components on Al-Si coating after heat treatment for 6 min at $900{ }^{\circ} \mathrm{C}$ through the line scan(a); average oxygen cps of the Al-Si coating upper part(b).
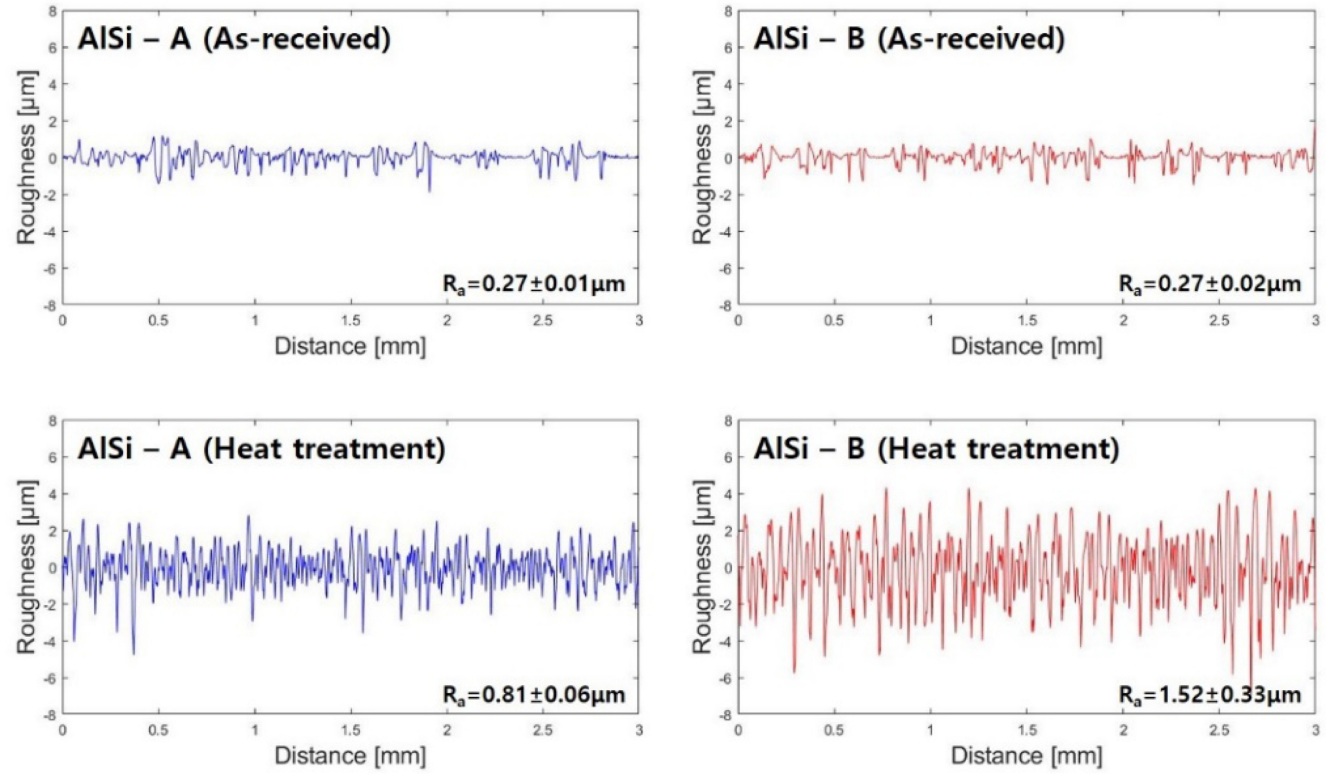

Fig. 7. Surface roughness of before(i.e., as-received) and after heat treatment for $6 \mathrm{~min}$ at $900{ }^{\circ} \mathrm{C}$.

$\mathrm{C}$ 는 시편을 몰딩한 재료의 주 성분으로써 $\mathrm{C}$ 성분이 급 격히 줄어드는 것을 통해 Line scan 결과에서 도금층의 분석 위치를 판단하였으며 $\mathrm{Al}, \mathrm{Fe}, \mathrm{Si}$ 의 분포 경향을 통해 도금층 각 상들의 구간을 정의하였다. 도금층에 대한 Line scan이 시작된 후 $\mathrm{Al}$ 이 줄어드는 구간, 즉 $\mathrm{LAZ}$ 전까지 $\mathrm{Fe}_{2} \mathrm{Al}_{5}$ 상의 구간이며 $\mathrm{LAZ}$ 은 $\mathrm{Fe}_{2} \mathrm{Al}_{2} \mathrm{Si}$ 상에 대한 구간이다. 이 후 $\mathrm{Al}$ 분포가 상승하는 것을 통해 $\mathrm{Fe}_{2} \mathrm{Al}_{5}$ 구간을 확인 하였으며 $\mathrm{Fe}$ 가 증가하고 $\mathrm{Al}$ 과 $\mathrm{Si}$ 의 분포가 줄어드는 구간 을 확산층으로 판단하였다. 소재에 따른 산화층 분포 정도 를 비교하기 위해 도금층 상층부인 $\mathrm{Fe}_{2} \mathrm{Al}_{5}$ 구간에서의 $\mathrm{O}$ 성분 평균 값으로 이를 비교하였다(그림 $6 \mathrm{~b}$ ). 도금층 상층 부에 대한 $\mathrm{O}$ 의 평균 분포를 비교하였을 때 $\mathrm{AlSi}-\mathrm{B}$ 소재
에서 더 큰 수치를 확인하였으며 그림 5 에서 $\mathrm{Al}$ 과 $\mathrm{O}$ 성 분이 분포가 유사하다는 점 등을 통해 $\mathrm{AlSi}-\mathrm{B}$ 소재의 도 금층 상층부에 산화층이 좀 더 발생한 것으로 판단하였다. 열처리 전·후에 따른 표면 조도 변화는 그림 7에 나타내 었다. 열처리 전의 시편의 경우 두 소재 각각 $0.27 \pm$ $0.01 \mu \mathrm{m}, 0.27 \pm 0.02 \mu \mathrm{m}$ 로 유사하지만 열처리 후에는 AlSi$\mathrm{A}$ 의 경우 $0.81 \pm 0.06 \mu \mathrm{m}, \mathrm{AlSi}-\mathrm{B}$ 는 $1.52 \pm 0.33 \mu \mathrm{m}$ 로 측정 되었다. 열처리 후 표면 조도 값이 차이나는 것은 그림 6 과 같이 산화물 분포 정도의 차이에서 비롯된 것으로 판단 된다. Pelcastre[16]는 금형의 표면 조도에 따른 마모 거동 의 차이를 정리하였다. Pelcastre는 시험 전 0.65 0.822, $1.2 \sim 2.74 \mu \mathrm{m}$ 표면 조도 값을 가지는 금형을 동일한 조건으 
로 왕복 마찰 시험을 시행한 후 표면을 분석하였을 때, 두 금형 표면에는 모두 연마 마모(Abrasive wear)와 접착 마 모(Adhesive wear)가 복합적으로 존재하였으며 특히 표면 조도 값이 큰 금형 표면에서 더 많은 접착 마모가 형성된 것으로 정리하였다. 이를 토대로 $\mathrm{AlSi}-\mathrm{A}, \mathrm{B}$ 의 유의미한 표 면 조도 수치 차이는 마모 거동에 있어서 영향이 있을 것 으로 사료된다.

\section{2 고온 마찰 시험}

그림 8 은 고온 마찰 시험에서 마찰 구간 10 부터 200 $\mathrm{mm}$ 까지의 마찰 계수 평균값을 나타낸 것이며, 표 4는 소 재 열처리 후 마찰 시험 시 금형 및 소재의 온도를 정리

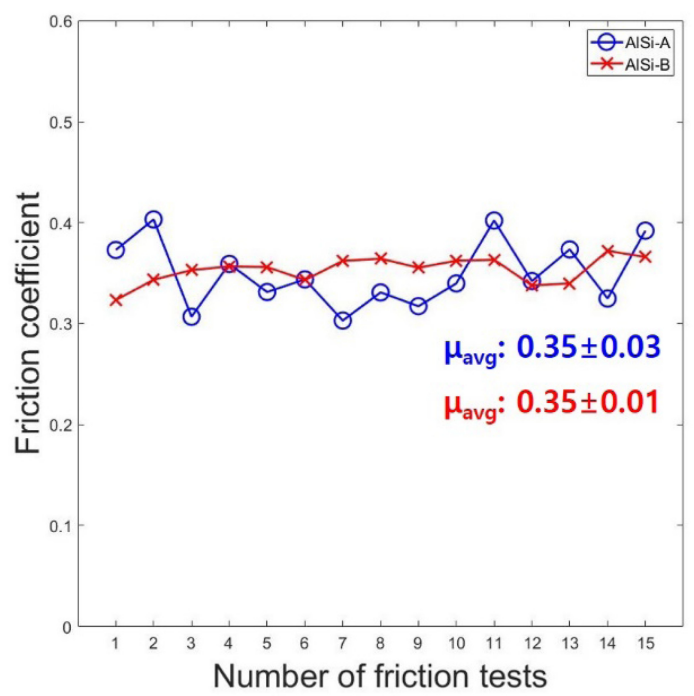

Fig. 8. Friction coefficient with respect to the number of friction tests that mimics the hot stamping environment.
한 것이다. 첫번째 시험에서 $\mathrm{AlSi}-\mathrm{A}$ 소재의 경우 0.373 으 로 $\mathrm{AlSi}-\mathrm{B}$ 의 0.3234 보다 비교적 큰 마찰 계수를 확인할 수 있었지만, 15 번의 고온 마찰 시험 후 평균값은 두 소 재 모두 약 0.35 로 거의 유사하였다. 하지만 산포도는 $\mathrm{AlSi}-\mathrm{A}$ 의 폭이 0.03 으로, $\mathrm{AlSi}-\mathrm{B}$ 의 0.01 보다 약 3 배정도 큰 폭을 보였다. 이는 마찰 계수 측면에서 표면 조도의 직

Table 4. Temperature of tool and specimen measured at 12 second after the specimen was heat treated (for $6 \mathrm{~min}$ at $900{ }^{\circ} \mathrm{C}$ ) and taken out of the furnace.

\begin{tabular}{ccccc}
\hline & \multicolumn{2}{c}{ AlSi-A } & \multicolumn{2}{c}{ AlSi-B } \\
\cline { 2 - 5 } Friction test & $\begin{array}{c}\text { Tool } \\
\left({ }^{\circ} \mathrm{C}\right)\end{array}$ & $\begin{array}{c}\text { Specimen } \\
\left({ }^{\circ} \mathrm{C}\right)\end{array}$ & $\begin{array}{c}\text { Tool } \\
\left({ }^{\circ} \mathrm{C}\right)\end{array}$ & $\begin{array}{c}\text { Specimen } \\
\left({ }^{\circ} \mathrm{C}\right)\end{array}$ \\
\hline 1 & 30 & 756 & 31 & 748 \\
2 & 33 & 770 & 37 & 738 \\
3 & 38 & 748 & 38 & 762 \\
4 & 31 & 758 & 30 & 753 \\
5 & 37 & 748 & 36 & 748 \\
6 & 35 & 756 & 30 & 745 \\
7 & 34 & 744 & 33 & 731 \\
8 & 30 & 730 & 38 & 742 \\
9 & 37 & 741 & 35 & 750 \\
10 & 38 & 749 & 30 & 751 \\
11 & 29 & 762 & 38 & 757 \\
12 & 37 & 730 & 38 & 769 \\
13 & 38 & 757 & 32 & 759 \\
14 & 40 & 742 & 33 & 756 \\
15 & 39 & 757 & 32 & 770 \\
\hline Average & 35 & 750 & 34 & 752 \\
Standard & 3.7 & 11.2 & 3.2 & 10.8 \\
Deviation & & & & \\
\hline & & & & \\
\hline
\end{tabular}

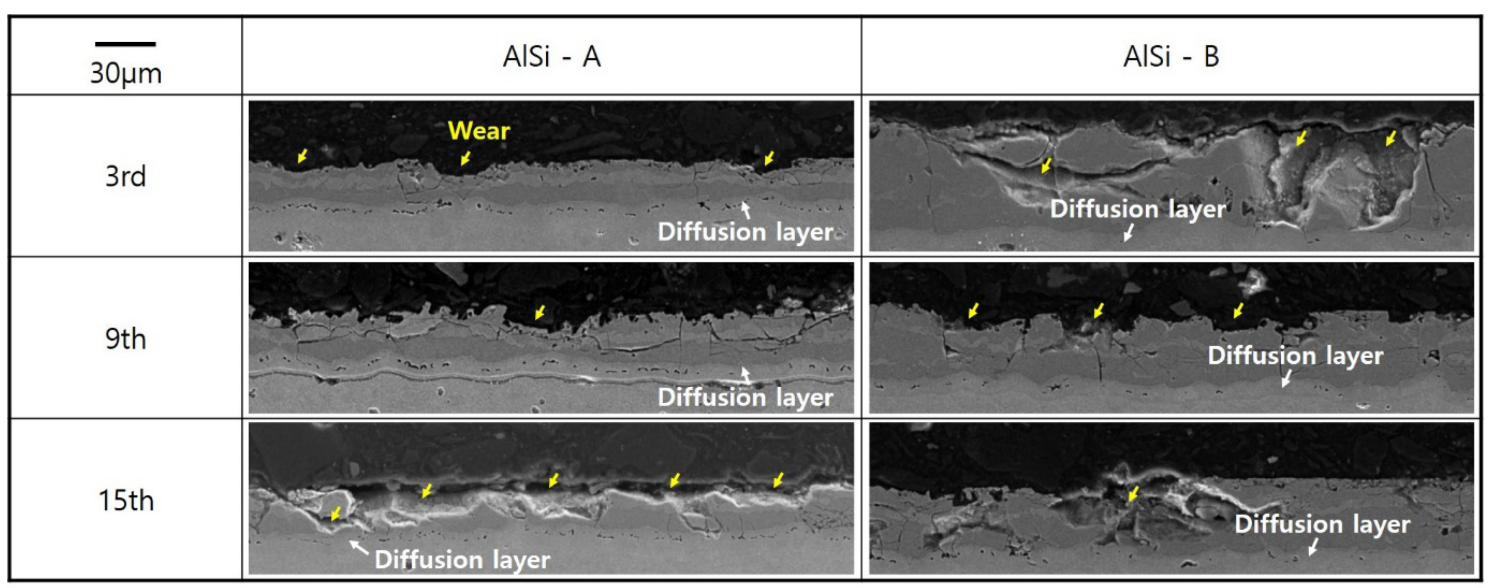

Fig. 9. SEM images of worn coating layer after 3rd, 9th and 15th friction tests; The yellow arrow indicated where the wear occurred (The friction direction is penetration in this figure). 

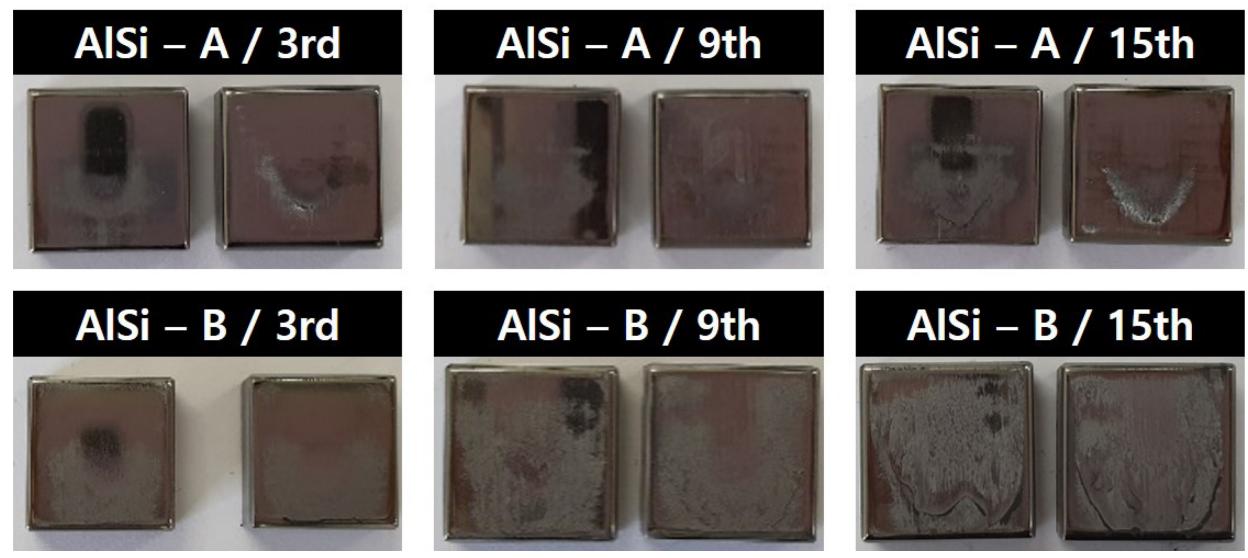

Fig. 10. Transferred coating material on to the tool surface after 3rd, 9th and 15th friction test (The friction direction is upward in this figure).

접적인 영향뿐만 아니라[32] 다른 영향이 있었음을 판단하 였으며 이를 확인하기 위하여 특정 순번 시편의 단면을 분 석하였다. 그림 9는 각 소재의 $3,9,15$ 번째 마찰 시험 후의 시편 단면을 나타낸 것이며 모든 시편들은 동일하게 마찰 거리 $140 \mathrm{~mm}$ 위치에서 분석하였다.

비교적 얇은 도금층인 AlSi-A의 경우 초기에는 부분적으 로 마모가 일어났으며 마찰 시험을 거듭 할수록 마모가 심 해 짐을 확인하였다. 15 번째의 경우에는 전체적으로 도금 층이 탈락하였으며 심한 곳은 확산층까지 마모가 일어났다. 반면 $\mathrm{AlSi}-\mathrm{B}$ 의 경우, 초기에는 $\mathrm{AlSi}-\mathrm{A}$ 와 유사하게 부분적 으로 마모가 일어났으나 그 정도는 비교적 심하였다. 하지 만 이는 일부분에 해당되며 전체적인 도금층은 남아있음을 확인할 수 있다. 열처리 후 도금층은 대부분 $\mathrm{Fe}_{2} \mathrm{Al}_{5}$ 와 $\mathrm{Fe}_{2} \mathrm{Al}_{2} \mathrm{Si}$ 상들인 반면 확산층은 비교적 무른 상인 $\alpha-\mathrm{Fe}$ 가 지배적으로 존재한다는 관점에서 마찰 시험의 반복에 따라 부분적으로 확산층까지 마모가 일어난 것은 AlSi-A 소재의 마찰 계수 변화에 영향을 미친 것으로 판단된다 [33].

\section{3 금형 마모}

그림 10 은 고온 마찰 시험 후 금형 표면을 보여주며 두 소재 모두 마찰 후 표면에 회색 물질이 존재하였다. 이는 시험이 반복 될수록 육안으로 확인 될 정도로 양이 점차 증가하였지만 두 소재 간에는 양적인 측면에서 차이를 보 였다.

표 5 는 특정 횟수의 마찰 시험 후 측정한 왼쪽과 오른 쪽 금형의 무게이며 그림 11은 왼쪽과 오른쪽 금형의 평 균 무게 증가량을 나타낸 그래프이다. 두 소재 대상으로 한 금형이 모두 마찰 시험 후 무게가 증가한 경향과 그림 10 의 금형 표면 형상을 근거로 금형에 접착 마모가 발생한
Table 5. Tool weight for left and right tool measured after friction test.

\begin{tabular}{ccccc}
\hline \multirow{2}{*}{$\begin{array}{c}\text { Friction } \\
\text { test }\end{array}$} & \multicolumn{2}{c}{ AlSi-A } & \multicolumn{2}{c}{ AlSi-B } \\
\cline { 2 - 5 } & $\begin{array}{c}\text { Left tool } \\
(\mathrm{g})\end{array}$ & $\begin{array}{c}\text { Right tool } \\
(\mathrm{g})\end{array}$ & $\begin{array}{c}\text { Left tool } \\
(\mathrm{g})\end{array}$ & $\begin{array}{c}\text { Right tool } \\
(\mathrm{g})\end{array}$ \\
\hline Before test & 27.38 & 27.28 & 27.23 & 27.36 \\
3 & 27.38 & 27.28 & 27.24 & 27.37 \\
6 & 27.38 & 27.28 & 27.25 & 27.37 \\
9 & 27.38 & 27.28 & 27.25 & 27.38 \\
12 & 27.39 & 27.29 & 27.26 & 27.38 \\
15 & 27.39 & 27.29 & 27.27 & 27.39 \\
\hline
\end{tabular}

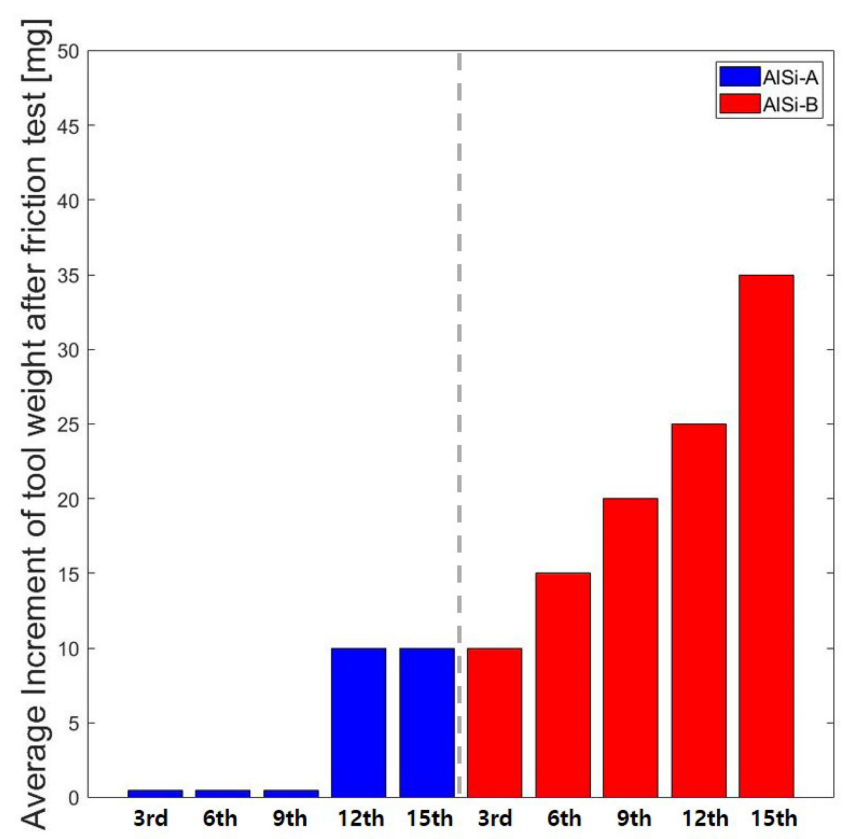

Fig. 11. Average increment of tool weight for left and right tool measured after friction test. 


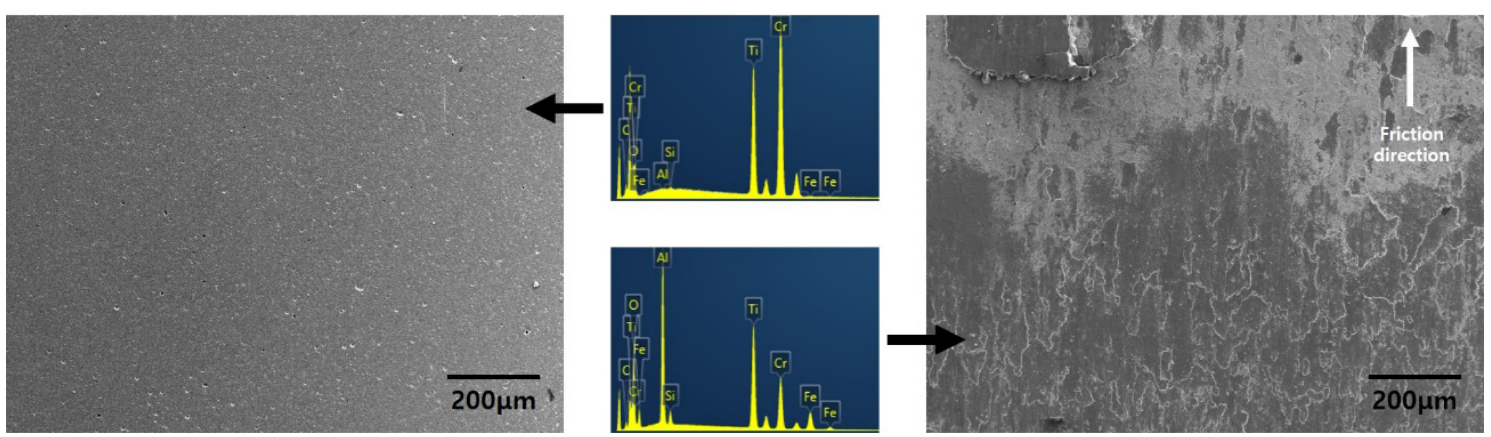

Fig. 12. SEM images of the tool center: (left) before the friction test and (right) after 15th friction test of AlSi-A specimen (The friction direction is upward in this figure).

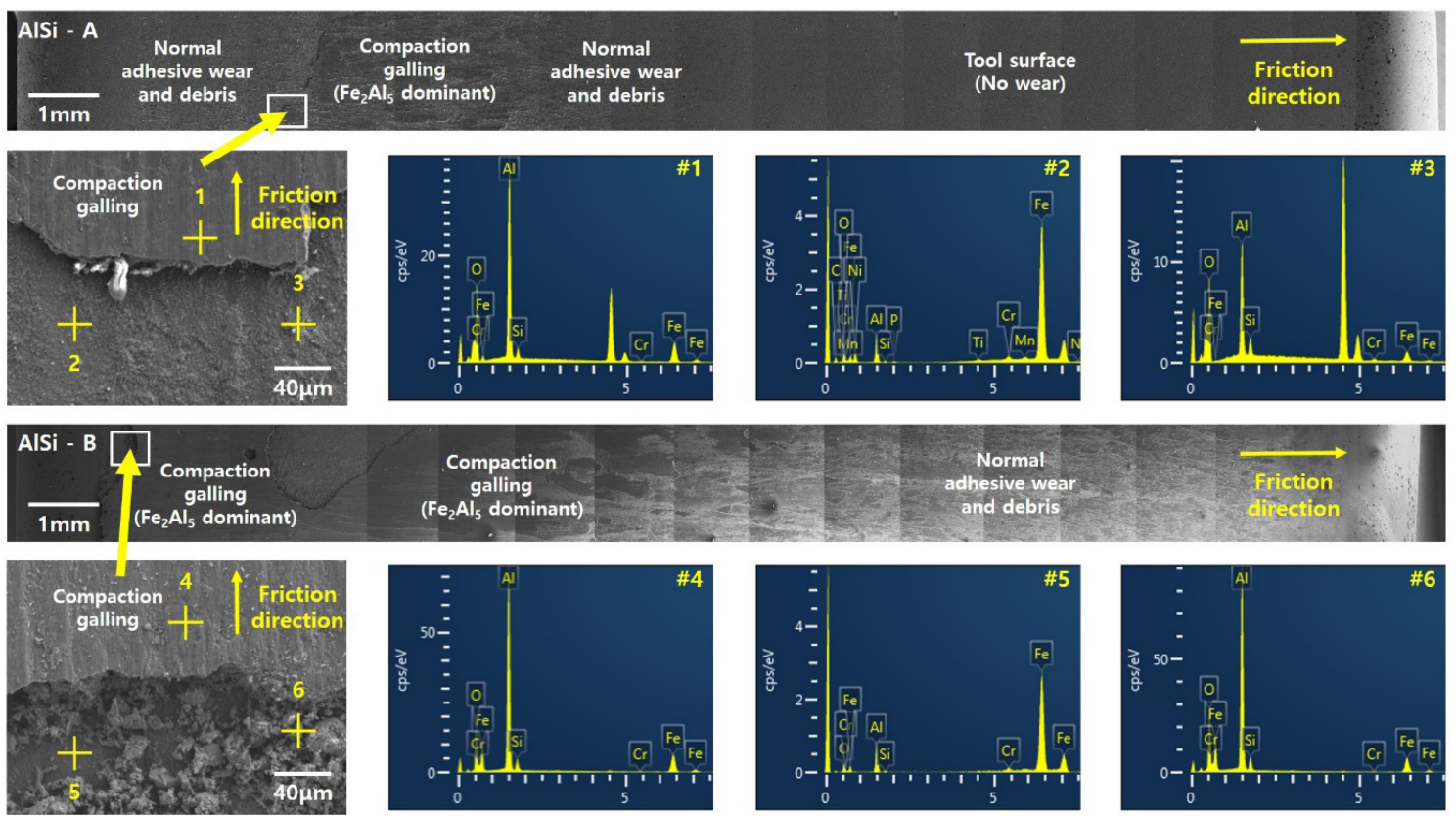

Fig. 13. SEM images showing wear behaviour of the right tool against Al-Si coated 22MnB5 after 15th friction test: (upper) AlSi-A and (lower) AlSi-B (The friction direction is left to right in this figure).

것으로 판단된다. AlSi-A 소재를 대상으로 한 3, 6, 9번째 마찰 시험 후 금형 무게는 거의 변화가 없었으며 12 번째 시험 후부터 금형 무게 증가량을 확인할 수 있었다. AlSi$\mathrm{B}$ 의 경우 $\mathrm{AlSi}-\mathrm{A}$ 소재를 대상으로 한 시험에 비해 금형 무게 증가량이 컷으며 15 번째 시험 후에는 약 3 배 이상의 금형 무게 증가량을 확인할 수 있었다. 이를 통해 두 소재 간에 접착 마모 정도의 차이가 발생한 것으로 판단하였다. 또한 그림 12에서 AlSi-A 금형 중앙 부의 시험 전·후 성 분 분석을 해당 접착 마모는 $\mathrm{Al}$ 과 $\mathrm{Fe}$ 계열의 금속간화합물 임을 확인할 수 있었다.

그림 13은 15번째 고온 마찰 시험 후 각 소재에 따른 오른쪽 금형의 최하단부 중앙부터 끝까지의 표면을 보여준 다. 금형 하단부는 마찰이 시작되는 부분으로 $\mathrm{AlSi}-\mathrm{A}$ 소재
의 경우 Normal adhesive wear 혹은 입자 형태로 금속간 화합물이 존재하였다. $\mathrm{AlSi}-\mathrm{B}$ 의 경우 하단부에서 입자 형 태와 마찰 시험이 반복됨에 따라 축적된 결과물인 Compaction galling[34]을 확인할 수 있었다. Venema[35] 는 $\mathrm{Al}-\mathrm{Si}$ 도금재를 대상으로 한 핫스탬핑 공정에서의 마모 메커니즘을 정리하였다. 금형과 소재 간에 접촉하는 단계 에서 주로 단단한 상 $\left(\mathrm{Fe}_{2} \mathrm{Al}_{5}\right)$ 에 의해 연마 마모가 일어나 며 취성의 특성을 띄는 $\mathrm{Fe}_{2} \mathrm{Al}_{5}$ 상은 입자 형태로 금형 표면 에 존재하게 된다. 마찰 시험이 반복되면 해당 입자들은 마찰 방향에 따라 금형 표면에서 이동하며 Normal adhesive wear[18,35,36]를 일으키고 특정 부분에 밀집되어 Compaction galling을 발생시킨다. Compaction galling이 발 생된 부분 이후로는 Normal adhesive wear와 Compaction 
galling이 복합적으로 일어난다고 정리하였다. 본 연구에서 도 이와 유사한 금형 마모를 확인할 수 있었다. 마찰이 시 작되는 금형 하단부에는 금속간화합물들이 마찰 방향에 따 라 입자와 Normal adhesive wear 형태로 존재하였으며 특정 부분에는 Compaction galling이 발생하였다. 그림 13 에 표시된 부분은 Compaction galling이 일어난 부분을 확대한 것으로 Compaction galling이 일어난 곳을 기준으 로 아래쪽과의 높낮이 차이가 존재하였다. Compaction galling의 성분 분석 결과는 1 번과 4 번이며 $\mathrm{Fe}_{2} \mathrm{Al}_{5}$ 상이 지배적으로 존재하는 것을 확인할 수 있었다. 높낮이 차이 가 나는 아래쪽에는 밝은 금속간화합물의 입자들과 비교적 어두운 표면을 확인할 수 있었다. 입자들의 성분 분석 결 과는 각각 3 번과 6 번으로 입자들은 $\mathrm{Fe}_{2} \mathrm{Al}_{5}$ 상이었으며 이 들의 크기는 $\mathrm{AlSi}-\mathrm{B}$ 에서 비교적 더 큰 것으로 확인되었다. 금형 표면의 성분 결과인 2 번과 5 번의 결과에서는 $\mathrm{Al}$ 보다 $\mathrm{Fe}$ 가 좀 더 지배적으로 검출되었으며 이를 통해 접착 마모 가 일어나지 않은 부분이 존재하는 것으로 판단하였다. Comapction galling 이 후 마찰 방향으로 두 소재 모두 Normal adhesive wear 등이 발생하였으나 AlSi-A 소재는 금형의 중앙부까지, $\mathrm{AlSi}-\mathrm{B}$ 는 금형의 끝까지 존재하였다.

그림 10 과 11 을 통해 마찰 시험 후 금형 표면 마모의 양적인 측면에서 차이가 있음을 알 수 있다. 취성 특성을 보이는 $\mathrm{Fe}_{2} \mathrm{Al}_{5}$ 상은 연마 마모에 의해 입자 형태로 금형 표면에 남게 되며, 이로 인해 접착 마모가 지배적으로 발 생하였다. Hisakado[37]는 연마 마모에 관하여 표면 조도 의 영향에 대해 연구하였으며 표면 조도 값 $(\tan \theta)$ 이 증가 함에 따라 연마 마모에 의한 마모량(wear volume) 또한 증가한다고 정리하였다. 그림 7과 같이 각 소재는 열처리 후 표면 조도 값에서 차이가 있었고 이는 고온 마찰 후 금형 표면에 존재하는 $\mathrm{Fe}_{2} \mathrm{Al}_{5}$ 입자에 영향을 끼쳤을 것이 며, 결과적으로 금형 마모에 지배적으로 발생한 접착 마모 의 양적인 측면에서 차이를 발생시켰을 것으로 판단된다.

\section{4. 결 론}

본 연구에서는 평면 마찰 방식의 자체 제작한 마찰기와 가열로를 이용하여 핫스탬핑 공정을 모사하였으며, 이를 통 해 $\mathrm{Al}-\mathrm{Si}$ 도금층 두께에 따른 $22 \mathrm{MnB} 5$ 강판의 마찰과 마 모에 대해 비교 분석을 실시하였다. 본 연구의 결과는 다 음과 같다.

(1) 동일한 열처리 조건에서 도금층의 구성은 산화층을 시작으로 $\mathrm{Fe}_{2} \mathrm{Al}_{5}, \mathrm{Fe}_{2} \mathrm{Al}_{2} \mathrm{Si}, \alpha-\mathrm{Fe}$ 등으로 구성되어 있었으 며 도금량과 무관한 것으로 확인되었다. 하지만 각 상들의
두께는 소재 간에 차이가 있음을 확인할 수 있었다.

(2) 평균 마찰 계수 평균 값은 유사하였으나 비교적 얇 은 도금층인 $\mathrm{AlSi}-\mathrm{A}$ 소재의 마찰 계수 산포도 폭이 더 컸 다. 이는 고온 마찰 시험 시 소재 도금층이 탈락하는 마모 의 영향인 것으로 판단된다. 15 번째 고온 마찰 시험 후 도금층이 두꺼운 $\mathrm{AlSi}-\mathrm{B}$ 소재는 전체적으로 도금층이 남 아있었으나 AlSi-A 소재는 도금층이 대다수 탈락하였으며 심한 곳은 확산층까지 마모가 발생하였다.

(3) 고온 마찰 시험 후 두 소재 모두 $\mathrm{Al}$ 과 $\mathrm{Fe}$ 계열의 금속간화합물이 금형 표면에 존재하였으며 접착 마모가 지 배적으로 발생하였다. 마모의 유형은 유사하나 양적인 측 면에서는 차이를 확인하였으며 이는 열처리 후 소재 표면 조도에 따른 연마 마모에서 발생하는 $\mathrm{Fe}_{2} \mathrm{Al}_{5}$ 마모량의 차 이인 것으로 판단된다.

결과적으로 핫스탬핑 공정에서 소재의 $\mathrm{Al}-\mathrm{Si}$ 도금층 두 께를 선정하는데 있어 소재의 마모와 금형의 마모 간에 적 절한 타협점이 필요할 것으로 사료된다.

\section{감사의 글}

This work was supported by POSCO in Korea and Research Assistance Program (2020) in the Incheon National University.

\section{REFERENCES}

1. T. Mega, K. Hasegawa, and H. Kawabe, JFE Tech. Rep. 4, 38 (2004).

2. S. Takagi, Y. Toji, M. Yoshino, and K. Hasegawa, ISIJ international 52, 316 (2012).

3. P. Åkerström, ph. D. Modelling and simulation of hot stamping, pp.5-23, Luleå tekniska universitet, Luleå (2006).

4. Y. Chang, Z.-h. Meng, L. Ying, X.-d. Li, N. Ma, and P. Hu, J. Iron. Steel. Res. Int. 18, 59 (2011).

5. Norrbottens Jaernverk AB, Manufacturing a hardened steel article, https://patents.google.com/patent/GB1490535A/en (1977).

6. M.-G. Lee, S.-J. Kim, H. N. Han, and W. C. Jeong, Int. J. Mech. Sci. 51, 888 (2009).

7. J. Jeong, S.-C. Park, G.-Y. Shin, C. W. Lee, T.-J. Kim, and M.-S. Choi, Korean J. Met. Mater. 56, 787 (2018)

8. A. Turetta, S. Bruschi, and A. Ghiotti, J. Mater. Process. Technol. 177, 396 (2006).

9. H. Karbasian and A. E. Tekkaya, J. Mater. Process. Technol. 210, 2103 (2010). 
10. Hao Zhao, Xiuli Hu, Junjia Cui, Zhongwen Xing, Met. Mater. Int. 25, 381 (2019)

11. K. Y. Kwon, N. H. Kim, and C. G. Kang, Open J. Adv. Mater. Res. 264, 241 (2011).

12. S. Goedicke, S. Sepeur, C. Breyer, M. Koeyer, and J. Lewandowski, CHS2 conf., pp.265-271, Luleå, Sweden (2009).

13. J. Hardell, L. Pelcastre, and B. Prakash, P. I. Mech. Eng. JJ. Eng. 224, 1139 (2010).

14. B. K. Choi, H. S. Son, and H. G. Kim, KSAE Annual Conf., pp.2757-2760, KSAE, Incheon, Korea (2009).

15. L. Pelcastre, J. Hardell, and B. Prakash, P. I. Mech. Eng. JJ. Eng. 225, 487 (2011).

16. L. Pelcastre, J. Hardell, and B. Prakash, NORDTRIB 2012, NTNU, Trondheim, Norway (2012).

17. L. Pelcastre, J. Hardell, A. Rolland, and B. Prakash, J. Mater. Process. Technol. 228, 117 (2016).

18. J. Venema, J. Hazrati, D. T. A. Matthews, R. A. Stegeman, and A. H. van den Boogaard, Wear 406, 149 (2018).

19. S.-J. Kim and H. Jang, Tribol. Lubr. 16, 365 (2000).

20. H. Y. Lee, Tribol. Lubr. 35, 139 (2019).

21. S. Choe, N. Nemati, and D. Kim, Tribol. Lubr. 35, 24 (2019).

22. H. Park and K.-H. Chung, Tribol. Lubr. 35, 30 (2019).
23. B. Bharat, Fundamentals of tribology and bridging the gap between the macro-and micro/nanoscales, Vol. 10, pp.261262, Springer Science \& Business Media, Berlin (2012).

24. W. Oliver, J. Mater. Res. 7, 1564 (1992).

25. T. Maitra and S. Gupta, Mater. Charact. 49, 293 (2002).

26. J. Jang, B. Joo, C. Van Tyne, and Y. Moon, P. I. Mech. Eng. J-J. Eng. 224, 87 (2010).

27. J. Kondratiuk and P. Kuhn, Wear 270, 839 (2011).

28. R. Veit, H. Hofmann, R. Kolleck, and S. Sikora, AIP Conf. Proc. 1315, 769 (2011).

29. D. W. Fan, and B. C. D. Cooman, Steel. Res. Int. 83, 412 (2012).

30. P. Matysik, S. Jóźwiak, and T. Czujko, Materials 8, 914 (2015).

31. P. L. Menezes and S. V. Kailas, Wear 267, 1534 (2009).

32. A. Moore and W. M. Tegart, P. Roy. Soc. A-Math. Phy. 212, 452 (1952).

33. L. Pelcastre, J. Hardell, and B. Prakash, Tribol. Int. 67, 263 (2013).

34. J. Venema, D. T. A. Matthews, J. Hazrati, J. Wörmann, and A. H. van den Boogaard, Wear 380, 137 (2017).

35. J. Pujante, M. Vilaseca, D. Casellas, and M. Riera, IDDRG Int. Conf., p.15, IDDRG, Linz, Austria (2016).

36. T. Hisakado, Wear 41, 179 (1977). 